I have supposed the left-hand total to be the larger. Write in the difference between the totals above the larger total copied down at the foot, and check by adding. Enter the addition-log table with this difference as ' $A$ ' and write the corresponding ' $B$ ' in the upper of the two remaining spaces. Add this ' $B$ ' to the total above it, and underline (to ensure you're not looking up the wrong figure), and find this final total in the table (top half of page) and you have your calculated Z.D. All that remains to get the intercept is to copy down your corrected obs. alt., and add. Any excess over 90 is Int. To, any defect from 90 will be Int. FROM.

\begin{tabular}{c|c}
\hline$p$, 'top' & $1 \sim d$, 'top' \\
\hline$l+d$, 'bottom' & $P$, 'bottom' \\
\hline sum $_{1}$ & $\operatorname{sum}_{2}$ \\
\hline 'B' & 'A' \\
\hline L hav $Z D$ & sum $_{1}$ \\
\hline
\end{tabular}

I am unable to explain this working more succinctly, but the process is quite quick and simple.

Greatly to my surprise, there is no English or American edition of these tables, and now that Europe is "partitioned" there is little immediate prospect of being able to obtain them. But their beauty and handiness remain unaffected, and I feel sure that sooner or later they will emerge from their regrettable obscurity, though it is too much to expect that the old Professor will live to see that day.

Yours faithfully,

B. R. Keir Moilliet.

\title{
CIRCUMVENTING THE DIMNESS OF THE RADAR SCREEN
}

SiR,

I am distressed at the way radar is being relegated from the forefront of the modern ship's wheelhouse to the darker recesses of her bridge. That daylight viewing of the P.P.I. requires the use of either shrouds or visors, or necessitates banishment of the screen to some dim corner seems to have become accepted; yet these are obstacles to good console-siting which might, I think, be circumvented.

As a young apprentice in the I 9 14-1 8 war, I found myself keeping a lookout from the bridge of one of the ships forming a convoy bringing American troops to the U.K. The sun shone from a cloudless sky but a fog lay low on the watera fog so dense that generally nothing could be seen, though, on occasion, masts and funnels and sometimes even bits of the superstructure of near neighbours loomed up from the fog. On that bridge was a set of different coloured glass viewing screens, each complete with little frame and handle. Beautiful toys to help a weary youngster while away the time. Experimenting with these things I became impressed that one particular screen, an 'orangey-yellow' piece of glass if my memory serves me right, made our near neighbours stand out more clearly from the glare of the sunlit fog than they did when looked for with unaided vision. 
Then in the recent war we learned much about 'night vision'-that ability of our eyes to accommodate themselves to 'seeing in the dark' - and we also learned that, like the emulsion on a photographic film, exposure to red light was much less detrimental to night vision than was exposure to other colours in the spectrum, or to white. As a compromise between white and red, orange lighting became common in chart rooms and was highly beneficial.

Now, there can be no gainsaying that conversance with the P.P.I.'s method of portraying one's surroundings is enhanced if the neophyte can, in clear weather, alternate his gaze between outlooking windows and the radar picture. Also, when one considers the numerous responsibilities of a solitary watchkeeper on the bridge of a ship in fog, these responsibilities would be much less burdensome were the radar screen in the forefront of the wheelhouse where he could look out into the fog, cast an eye upon the helmsman, listen, reach for the telegraph or whistle control whilst keeping watch on the P.P.I. and giving birth to any necessary radar plotting. A recess at the back of the wheelhouse or the chart room puts the burden at a premium.

The forefront of a wheelhouse offers no obstacles to the viewing of a radar screen at night, but in a sunlit fog_-_!

That all the wheelhouse windows were shuttered over in daytime with red, 'orangey-yellow', other, or even multi-coloured transparent glass would not be detrimental to the clear-weather lookout. And in a daytime fog, if it were found that the experience recounted in the second paragraph was not the figment of a youthful imagination but arose from fact, and if a 'perfect' shade and density of colour could be found, then the daytime colour screening of all light entering the wheelhouse might be advantageous to the lookout from the bridge in daytime fog. If, also, this 'perfect' colour were one which induced a sufficient degree of night vision, then, perhaps, the wheelhouse forefront could become a suitable position for daylight observation of the radar screen without recourse to shrouds or visors or other misbegotten aids to darkness. A comparatively short open collar rising from the screen would be necessary to cast shadow on the actual P.P.I., but such a collar would not contort the observer's viewing posture, nor would it restrict his freedom of movement to the point of interference with his other responsibilities.

On several occasions in the last few years I have made suggestions that experiment be used to prove or disprove the practicability of my contention, but to the best of my knowledge such test has only been nibbled at with coloured spectacles. Such nibbling, I fear, must be of negligible value. On one occasion I made this 'coloured spectacles' test' myself, and found that the forty seconds I had hat to stand at the visor before I could view the screen clearly in daylight became reduced to less than half when I had worn sun-glasses for ten minutes before applying myself to the visor. But those sun-glasses were of random colour and density, and might have been far from best suited for promotion of night vision or for seeing into fog. As it was, there was plenty of sunlight but not a drop of fog.

27 September $195^{\circ}$. Aden.

\author{
Yours truly, \\ E. M. RoBb. \\ Master, m.v. Eurybates.
}

